\title{
La risa de paso. Hacia una politización del arte en Walter Benjamin
}

\author{
Daniel Lesmes \\ Universidad Complutense de Madrid \\ jdlesmes@ucm.es
}

RESUMEN: La risa es uno de los temas menos estudiados en la obra de Walter Benjamin; sin embargo, constituye una de las claves para la comprensión de lo que el crítico alemán consideró que podría ser una politización del arte. En este artículo tratamos de desgranar el lugar de la risa en la teoría estética y política de Benjamin a partir de su conferencia «El autor como productor». Desde ese punto nos proponemos introducir su lectura de Bertolt Brecht, así como su polémica con Theodor W. Adorno.

PALABRAS CLAVE: Walter Benjamin; Risa; Cómico; Cine; Teatro; Estética y Política.

\section{Laughter by the Way: Toward a Politicization of Art in Walter Benjamin}

ABSTRACT: Laughter is one of the lesser studied subjects in the work of Walter Benjamin. However, it constitutes one of the keys to understanding what the German critic considered might be a politicization of art. In this article we attempt to describe the place of laughter in Benjamin's aesthetic and political theory as it is presented in his lecture «The Author as a Producer». From that point we propose to introduce his reading of Bertolt Brecht, as well as his controversy with Theodor W. Adorno.

KEYWORDS: Walter Benjamin; Laughter; Comedy; Cinema; Theater; Aesthetics and Politics.

Recibido: 18 de abril de 2017 / Aceptado: 07 de julio de 2017.

\section{La risa de Benjamin}

Anoto de paso que, para pensar, no hay mejor comienzo que la risa. En especial, la sacudida del diafragma suele ofrecerle al pensamiento mejores oportunidades que la del alma (Benjamin, 1977a: 699)

A pesar de esta anotación que Walter Benjamin hizo en su conferencia sobre «El autor como productor» no parece que él riera demasiado. Más bien, su imagen suele identificarse con el pensador melancólico que escribió sobre ese ángel de la historia que contempla «una única catástrofe amontonando incansablemente ruina tras ruina» (2008a: 310). Por eso sorprende tanto que haga ese apunte sobre la risa; tanto, digo, como aún me maravilla encontrar, entre los gestos introspectivos con que tantas veces posó Benjamin frente a la cámara, esta otra fotografía de 1931 donde aparece mucho más relajado, tumbado y riendo a sus anchas junto a varios compañeros del círculo de Bertolt Brecht [1]. La risa de Benjamin se nos ha mostrado mucho menos que sus reflexiones sobre lo cómico, aunque tampoco es que éstas se destaquen demasiado en los estudios que se le dedican. En cualquier caso, sospecho que, pese a su seriedad, lo de la risa no era una simple anécdota para Benjamin; de hecho, tal vez conforme una de las claves para entender su posición como intelectual.

Poco antes de dar aquella conferencia -antes incluso de que le hicieran esa foto en que aparece riendo-, Benjamin participó en otro tipo de encuentros en torno a sustancias como el hachís, de cuya embriaguez decía que "comienza en

Cómo citar este artículo: LESMES, Daniel, «La risa de paso. Hacia una politización del arte en Walter Benjamin", Boletín de Arte-UMA, n. ${ }^{\circ} 38$, Departamento de Historia del Arte, Universidad de Málaga, 2017, pp. 117-126, ISSN: 0211-8483, DOI: http://dx.doi.org/10.24310/BoLArte.2017.v0i38.3260 
carcajadas, o [con] una risa feliz y más serena» (2010a: 165). En uno de aquellos «protocolos», como Benjamin llamaba a esas reuniones, Ernst Bloch observó precisamente que a través de esa risa embriagada «están todas las cosas bajo un cristal», que están «sin aura» (1995: 76). Con este apunte Bloch anunciaba uno de los conceptos clave que más tarde desarrollaría Benjamin, y tal vez por ahí se entienda mejor el calado de la afirmación de que el pensamiento puede comenzar con la risa. Si el aura se va de las cosas que nos hacen reír será porque también cede el misterio ante esa suerte de risa bárbara en la que Benjamin depositó no pocas esperanzas (2007a: 220). Digamos que la risa se abre, y por esa apertura también ella misma se nos escapa cuando ya ha hecho vacilar a la autoridad aurática. Porque su componente embriagado resulta un «aflojamiento del yo» (2007b: 303), ya es la risa floja; pero también, porque la embriaguez sólo se cumple completamente en comunidad, como el propio Benjamin afirma (2010b: 87), uno se parte y se reparte de risa.

Al volver sobre las anotaciones a propósito de la risa que Benjamin dejó caer aquí y allá, parece que nunca ríe mejor quien ríe el último, sino quien ríe con los demás. Y esto por la sencilla razón de que aquél ya tiene clavada la espina de una desgracia, pues la risa del último -la del ganador- puede ser cólera filtrada en la astucia de quien causa temor, pero en ningún caso es una risa que pueda repartirse con franqueza. Digamos que la risa únicamente despliega esa misma embriaguez cuando es la risa de todos: no la del filósofo que ve reír, sino la que a todos nos entra al ver que la risa misma resiste a toda abstracción, que es toda ella cuerpo, y que con sus sacudidas de diafragma, como decía Benjamin, aún se hace contagiosa y hasta extraordinariamente común. Así me parece que hablaba Benjamin en el Instituto de Estudios sobre el Fascismo de París, con aquella conferencia sobre «El autor como productor» en la que acercaba la risa a la épica a través de los dos rasgos que acabo de introducir: lo embriagado y lo colectivo.

\section{La risa y la épica}

Épico es el teatro de Bertolt Brecht al que precisamente Benjamin se refería en su conferencia con esa anotación sobre la risa, aunque fuera de paso, pues «el teatro épico sólo es exuberante en ocasiones para que nos riamos» (2009a:
313). En opinión de Benjamin la risa coincide con esos momentos en los que el teatro de Brecht hace por vez primera lugar al pensamiento, es decir, con el instante en que se expone de repente la extraña situación en la que en verdad se encuentran sus actores. La risa coincide pues con «la interrupción de la acción». Por ejemplo, cuando sin venir a cuento todos allí se ponen a cantar; entonces «el proceso se interrumpe, y lo que en su lugar viene a mostrarse es la situación ante la mirada de quien ahora le es extraño» (2009a: 312). Así se asombran los propios actores, que ven lo extraño de su propia situación; pero también se expone la situación del público que, igualmente extrañado, rompe a reír.

Tal era, según Benjamin, la técnica de Brecht en este punto: la acción se interrumpe y aquello es la risa del desconcierto. Pero no se trata de un simple efecto cómico, puesto que en esa risa se palpa también la completa desilusión de quienes ya no pueden encontrar una conexión emocional con la escena y dejan de identificarse con lo que en ella transcurre. A esta característica le dedicó Benjamin mucha atención en otros artículos en los que destacaba la imposibilidad de localizar en el teatro de Brecht algo así como una catarsis o una purga de los afectos mediante la identificación con el héroe trágico (2009b: 140). Por el contrario, con esta interrupción marcada por la risa incluso la historia que se cuenta parece perder su aura mítica, ese aura, digo, que se concentraba en un héroe cuyo destino tantas veces contemplamos en el teatro clásico como si fuese también el nuestro. Pero frente a esta suerte de empatía con el héroe, tan descreída irrumpe la risa en el teatro de Brecht que con ella no sólo descubrimos que nunca encontraremos en nuestro destino el mismo calor con que se quema el destino del héroe (2009c: 59); no sólo quiebra la risa todo tipo de identificación en este sentido, sino que también manifiesta un tipo de dicha completamente impropia de la idea misma de destino, pues es una risa dichosa como la que en ningún caso alcanza al héroe trágico, cuya alegría procede de alguna triquiñuela que al final siempre vuelve a desembocar en la culpa, aunque solo sea porque el héroe se alegra de engañar a los mismos dioses que lo crearon (2008b: 175-182). En contraste, la risa que en ocasiones irrumpe en el teatro épico es de todo punto inocente, aunque sea violenta. Se podría decir que es la "carcajada limpia» que comienza con ese descubrimiento que es también un «distanciamiento» de la propia situación (2009b: 59). Si como decía Benjamin la 


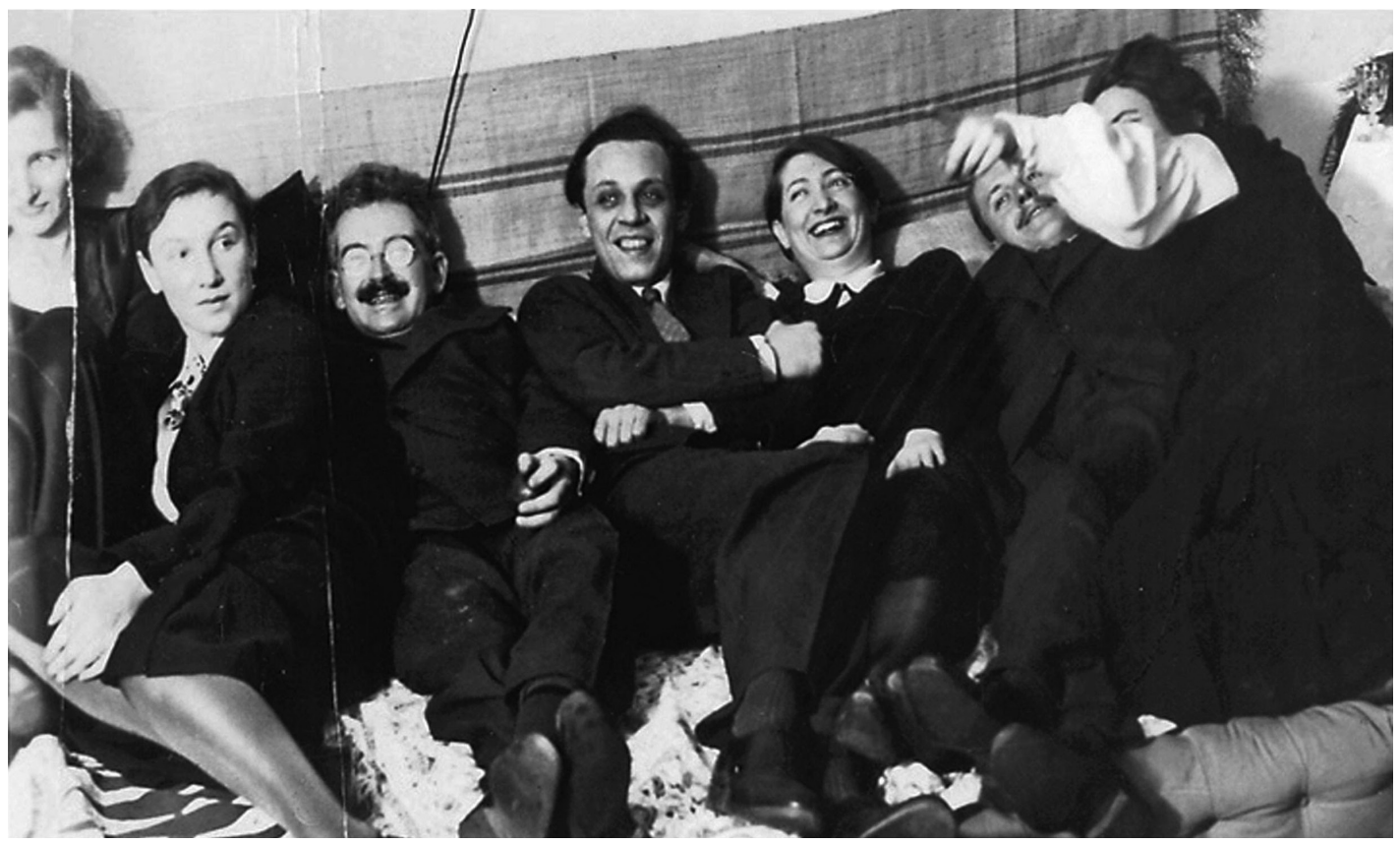

1. Fotografía de la navidad de 1931, en Berliner Strasse 45, Archivo de Elisabeth Hauptmann

risa es el mejor comienzo para pensar, es porque la interrupción que trae consigo también conforma el momento educativo del teatro épico. Por eso se podría afirmar que la risa de la que Benjamin hablaba es la de quienes aprenden algo en tanto que se echan a reír.

\section{Contra el hombre espiritual}

Uno podría pensar que hablar de la risa en el punto más intenso de una conferencia sobre arte y política ( «El autor como productor») también puede provocar algún desconcierto, incluso podría suscitar cierta hilaridad. Que Benjamin haga una afirmación tal sobre la risa en mitad de una conferencia de lo más comprometida, donde la urgencia marca el tono (pues no en vano fue escrita apenas Hitler tomó el poder), puede resultar bastante extraño. $Y$ en efecto, da que pensar, pues de algún modo también interrumpe la seriedad del momento, aunque no precisamente para lograr una distensión en el auditorio, sino para saltar, como en seguida vemos, a otra parte, incluso con mayor seriedad. De hecho, punto y aparte, Benjamin exponía cuál debía ser la tarea más urgente de un autor, de un artista o de un intelectual: «reflexionar sobre su propia posición en el proceso de producción», y esto en la medida en que tal proceso condiciona el completo de las relaciones sociales (2009a: 305, 313).

Benjamin sabía de sobra que todo autor está ya posicionado de antemano, que tiene un dónde y un para qué en el conjunto de las relaciones sociales, y lo que de hecho le preocupaba era que, pensándose en principio a la contra, dicha posición podía estar trabajando en el fondo a favor de los mismos procesos que amenazan todo pensamiento crítico. Sin duda por eso era para él tan urgente conocer en qué medida el aire que empuja los procesos de producción del capitalismo también puede aprovechar el aliento crítico. Era preciso, por tanto, reflexionar sobre el movimiento en el movimiento, sobre la tendencia en la tendencia que, en su época, él observaba como una creciente racionalización; o por decirlo con sus propias palabras: como «un proceso de producción espiritual» (Prozeß der geistigen Produktion) en el cual el fascismo se mostraba ya como posible desembocadura del capitalismo, y donde el «espíritu» (Geist) bien podría entenderse como razón abstracta e incluso como dispositivo de abstracción, y, por cierto, nunca al modo en que por 
ejemplo un dadaísta como Raoul Hausmann afirmaba en su Panfleto contra la concepción de la vida en Weimer que «el espíritu es una técnica» (1999: 209), pues, en definitiva, habría que entender aquí el término Geist precisamente en el sentido en que los dadaístas, a quienes entonces elogiaba Benjamin, arremetieron contra el expresionismo por hacer del artista un perfecto hombre espiritual.

La imagen melancólica que habitualmente nos hacemos de Benjamin corre siempre el peligro de caer en esta suerte de estereotipo romántico. Sin embargo, frente a este mismo perfil, él no dudaba en establecer una sutil filiación entre la creciente estetización de la política y una logocracia que, como "gobierno del espíritu», sólo podría tener su avanzadilla en ese hombre espiritual, es decir, en el intelectual, en el artista. Todas esas voces opuestas al estrago que el capitalismo produce en las más altas manifestaciones del espíritu humano eran puestas por Benjamin bajo sospecha desde su signo aristocratizante, ya que la tarea misma de conocer el lugar que ocupa el autor en el proceso de producción era para él de todo punto contraria a «entenderse en calidad de «espiritual» (2009a: 314). Digamos que quien reclama tal título y al mismo tiempo pretende transformar la sociedad ocupa un lugar imposible, pues, incluso si apela al sentido común, por su propio espíritu le es imposible hacerlo sin la convicción de que el talento artístico y la inteligencia son muy poco comunes. Para Benjamin, esa suerte de melancolía con la que algunos se lamentan de lo poco que pueden hacer como intelectuales o como artistas no hacía más que ocultar la nostalgia de una aristocracia cuyas lágrimas ocultan el temor a la propia precarización al tiempo que sacan a relucir la belleza de una lucha contra la miseria que bien podría convertirse en un objeto más para el consumo (2009a: 309).

Desde luego, los rasgos conformistas de ese inconformismo debían de resultar tan evidentes para Benjamin como más tarde lo sería para Theodor W. Adorno el hecho de que la lucha política puede adquirir un valor estético de prestigio (1998: 132; 2004: 274-275). Y precisamente contra ese prestigio parece que Benjamin invocaba en sus textos el carácter destructivo de una risa a la que, por cierto, Adorno no dejaría de mostrar su más franco temor. De hecho, probablemente no hubiera un motivo más grave para la polémica entre ambos, pues si Adorno recelaba de la risa como signo del populacho más cruel, para Benjamin esa misma risa po- día coincidir en el intelectual con la toma de conciencia de cuán extraña se había tornado su posición en un tiempo de crisis evidente, un tiempo, a fin de cuentas, cada vez más marcado por la cultura de masas.

Los distintos posicionamientos escrutados por Benjamin en su conferencia de 1934 revelan su interés en esta misma coincidencia, pues no cabe duda de que si él se alineaba allí con el contraprograma dadaísta era precisamente porque el dadaísmo se había fundado en «una cuestión de conexión que en principio queda algo interrumpida» (Ball, 2005: 372). Obviamente, en el caso de Dadá esa interrupción suponía ya un paso desviado en la risa, el paso mismo que nos hace reír, el traspiés, la caída, pues si la risa aún puede salirnos al paso, en su acceso -el acceso de risa- encuentra lugar la interrupción de la acción, y así mismo había dicho el dadaísta Hausmann: "Nosotros queremos reír», reír de la ciencia, de la cultura, y, sobre todo, reírse de los propios intelectuales (1999: 209).

\section{La risa de los pobres}

Los modos con los que habitualmente nos referimos al acto de reír son en este punto bastante elocuentes: nos partimos, nos tronchamos, nos descacharramos, y precisamente en este sentido habría que entender aquí la risa como interrupción, como separación violenta, como cesura. Desde luego que existen otras formas de interrupción, y a este respecto se encuentran entre los escritos de Benjamin algunos ejemplos encantadores por su sencillez, como ése en que el sonido del teléfono en la casa paterna le entusiasmaba cuando él era niño, pues «equivalía a una señal de alarma, la cual no perturbaba solamente la siesta de [sus] padres, sino también la época de la historia en cuyo seno ellos descansaban» (2010c: 185). En este caso se podría decir que despertar del sueño, o de la época, en fin, despertar de la época del sueño es el darse propio de la interrupción. Y así como la risa surgía de paso cuando Benjamin se ocupaba de exponer la tarea que ha de realizar un autor comprometido, así también se posicionaba la risa de Benjamin en un punto preciso de la época, ese punto en el cual «la sofocante riqueza de ideas» $y$ «el despliegue formidable de la técnica» vienen acompañados de una pobreza aún mayor (2007a: 217). 
Benjamin dedicó en 1933 un importante artículo a este tipo de pobreza que él veía aumentar desde los años de la Gran Guerra, una pobreza que, a sus ojos, concernía en último término a la experiencia: Erfahrung und Armut, una pobreza, pues, que no sólo incumbe a experiencias privadas sino a la experiencia de la humanidad en su conjunto, ya que nada del saber acumulado a lo largo de la historia parece servirnos ahora, y, de hecho, más bien se diría que la desechamos como quien tira los zapatos viejos y cree firmemente que lo mejor es comenzar de nuevo. Se trata de una pobreza surgida del deseo mismo y por eso podría también considerarse una suerte de barbarie opuesta a la idea misma de cultura. En este sentido, para saber cuán pobres somos sólo habría que ver cómo desacredita el desarrollo técnico la experiencia que puedan tener nuestras manos; en fin, sólo habría que darse cuenta de que en un mundo en el cual la «novedad» se ha convertido en norma no sirve de nada toda esa experiencia acumulada y transmitida de generación en generación. Pero más que a esas señales de todo punto negativas, Benjamin prestaba su atención a esa nueva barbarie como deseo de despojarnos de toda tradición, una barbarie cuya máxima expresión sonaba en sus oídos como una gran carcajada: por ejemplo, la que reverbera en los cines con películas como las de Chaplin, tan en boga en los años treinta. Quienes ríen así, como durante un momento también lo había hecho Dadá, no hacen sino sacudirse, al modo en que lo haría un perrillo recién salido del agua, todo lo que les pesa hasta hacer visible su pobre y quebradizo cuerpo. $Y$ es que para Benjamin siempre ríen «los pobres»; es decir, ríen quienes se han visto obligados por la crisis a empeñar pedazo a pedazo la herencia de la humanidad (2007a: 221). Pero esa risa no es el consuelo de lo trágico, sino la risa que hace saltar la cadena que unía su propio destino a la pobreza, la que impugna la ley que impone el estigma de haber cometido algún delito por el cual, de hecho, nos hemos vuelto pobres: es la risa que refuta la condena y desmiente la antiquísima culpabilidad de quien lo ha perdido todo.

Las cosas que nos hacen reír a carcajada limpia puede que no sean más que mamarrachadas, bárbaras por otra parte, puesto que la risa de quien es así de pobre -y aún valora su pobreza como grado de honestidad- no va más allá de lo estrictamente corporal. Y así se ríen los pobres del cuerpo asombrosamente resistente que muestran, por ejemplo, los dibujos animados; se ríen del cuerpo que se estira y se encoge como el fuelle de un acordeón. Se podría decir que ésa es la risa en la cual se hace patente «cómo hace el tonto la humanidad» (2009c: 61); sin embargo, también con esa pobreza se revela lo que Benjamin le exige al intelectual y al artista: conocer lo pobre que a fin de cuentas es y cuánto lo ha de ser aún para empezar de cero. En efecto, la risa sería una suerte de grado cero de la cultura y por eso mismo puede decir Benjamin que «la humanidad se prepara para sobrevivir a la cultura si es preciso, y lo más importante es que lo hace riendo» (2007a: 222).

Sin embargo, para Benjamin la risa es también el punto más degradado de la palabra; y desde luego que está incluso por debajo de ella, como en esas viñetas que aparecen en los periódicos bajo el rótulo de «Sin palabras». Si Benjamin advertía que el periódico es «el escenario de la degradación total de la palabra», ¡cuánto más degradada no estará en ese tipo de risa! Aunque es precisamente en ese punto de decadencia donde para Benjamin aún podía incubarse la salvación misma de la palabra y, por ende, de todo a cuanto apunta esa pobreza (2009d: 240). Precisamente por eso debía de ser ésa una risa liberadora y compartida; la risa que a uno le quita un peso de encima y repara del hastío como el sueño repara del cansancio, pero también la que se comparte en aquello que los sueños de los seres humanos han producido. Sueños, digo, como en el fondo lo son esos personajes de dibujos animados de cuyo cuerpo surgen prodigios «que no sólo superan los prodigios técnicos, sino que se ríen de ellos» (2007a: 221).

\section{La polémica de Benjamin con Adorno}

Ahora bien, si acaso pudiéramos pensar que en estas reflexiones rezuma alguna ingenuidad, lo cierto es que Adorno se nos ha adelantado: "La risa del espectador de cine -le escribió a Benjamin apenas acabó de leer su ensayo sobre «La obra de arte en la época de su reproductibilidad técnica»- no es ni buena ni revolucionaria, sino que está llena del peor sadismo burgués» (1998b: 136). Y peor aún lo pintaría Adorno unos años después junto a su colega Max Horkheimer: como si la risa del cine cómico mostrarse a las claras que también son suyos los dientes del fascismo, «la diversión organizada se convierte en calidad de crueldad» (2006: 183). Para Adorno esos dibujos animados con los que la gente se empezaba en- 
tonces a divertir tanto no hacían sino acostumbrar al espectador a los palos que él mismo iba a recibir y a los que en cierto momento le podía tocar dar. Entre tantos palos no es extraño que Adorno entendiera la risa en relación con el miedo, pues bien que tiene motivos para reír quien escapa de ellos; pero quien no puede escapar, porque no se atreve o porque ni siquiera ha caído en la cuenta de que lo puede hacer, a éste le está reservada sin duda otra solución: la de ponerse de parte de aquel a quien teme y gozar con los palos que a otros les caen y a él no le dan. Y justo en esta posición se encontraba a ojos de Adorno el colectivo de los que ríen, y por eso mismo le resultaba tan absurdo que Benjamin vinculase una actitud crítica a la fruición de los espectadores, como de hecho señala en su ensayo sobre la obra de arte (2008c: 74-75).

Para Benjamin, sin embargo, la risa que provocaba el vodevil cinematográfico contaba con una característica muy particular, y es que si aún podía coincidir con una actitud crítica era precisamente porque su significación social comenzaba a hacer tan cercana a la obra de arte que casi se puede tocar. "Lo que llamábamos "arte" tiene ahora su comienzo a dos metros del cuerpo» (2009e: 232), decía Benjamin, pero con la risa incluso esos dos metros podían acortarse, aunque no fuese precisamente en un lugar reservado al gran arte. Cuando Adorno afirme más tarde (en su Teoría estética) que el arte se niega a ser definido y que su concepto sólo puede caracterizarse por "dirigirse contra lo que conforma su propio concepto», sin duda también caerá en la cuenta de que el arte puede volverse incierto hasta la médula, tan incierto como lo es ahora su lugar (2004a: 9-10). Pero la idea de que el arte se define por su lugar, por incierto que éste sea, tiene como contrapartida el hecho de que el arte está siempre fuera de sí. Así, lo que los dadaístas legaban al pensamiento de Benjamin -como diciendo: «mirad bien, el tiempo hace estallar el marco que protege vuestros cuadros; el trozo más pequeño procedente de la vida cotidiana dice mucho más que la pintura» (2009a: 306)- eso mismo lo escuchaba también él en la risa del arte. Porque está siempre fuera de marco también se podría decir que es la interrupción en lo aurático de ese mismo concepto -del arte- que no se deja coger por cercano que pueda parecer. Así, la risa de la masa, en su completa desinhibición, no sólo nos toca sino que irrumpe y desarma el mito, aunque sea con una violencia muy distinta a la violencia mítica.
Digamos que esa risa profana el residuo cultual que aún queda en el arte tras el proceso de secularización que Benjamin siguió con tanta atención (2008c: 56). Del mismo modo en que la secularización política de conceptos teológicos traslada la monarquía celeste a una monarquía terrenal dejando intacto el poder, como afirma Agamben (2005: 102), también podría decirse que con la secularización del arte queda transformado el ritual, sin que en ningún caso éste desaparezca. Lo que constituye el punto de entrecruzamiento entre arte y política, cuyo momento Benjamin trataba de pensar como el instante en que la función social del arte pasa de fundarse en el ritual a hacerlo en la política (2008c: 59), es asimismo un cambio en la forma de repartirse ese poder. Pero si ese instante en que la política y el arte vienen a coincidir, por así decirlo, con el cosquilleo que siente el cuerpo colectivo al sumergir dentro de sí la obra arte en vez de ensimismarse con ella, si coincide de hecho con la interrupción en la risa, aún puede seguir resultando efectiva la crítica de Adorno. Donde Benjamin observaba que el mismo público que se muestra reaccionario ante el arte de vanguardia es el que más se entusiasma con una película de Chaplin, Adorno entendió que un reaccionario puede convertirse en vanguardista con solo aprehender esa película de un modo objetivo, lo cual no le parecía sino una completa romantización del asunto (1998b: 136). Y desde luego que Adorno tenía sus razones para sostener esa opinión, si es que, como él pensaba, de esa risa tan terrible que suelta la masa acaso puede resultar una mayor alienación. Pensémoslo por un momento: si el descreimiento que muestra la risa no cayera contra la autoridad que la somete, sino que, indirectamente, fuese el signo más convencido de su reconocimiento y, por tanto, cayera contra los seres humanos en su incapacidad de reconciliación, si eso fuese lo que tiene lugar en la risa de los espectadores de los filmes cómicos, entonces sí que tendríamos que afirmar con Adorno que «el colectivo de los que ríen es una parodia de la verdadera humanidad» (2006: 185). A fin de cuentas, resulta más que probable que con esa risa se «naturalice» una situación de completo sometimiento de los cuerpos, de manera que nunca pueda convertirse en lo que Adorno llamaba una «risa reconciliada». Vista así, es probable, incluso, que la risa nunca se desligue del componente de castigo que Adorno denunciaba. 


\section{L'art pour l'art y lo cómico absoluto}

Sin embargo, frente a las sospechas que Adorno albergaba sobre la risa de los «pobres», lo cierto es que también Benjamin siguió el rastro de esa risa terrible a la que el fascismo le viene siempre detrás. Y así se encontró con el culte de la blague, ese culto a la broma cuyos primeros nudos fecundantes localizaba en Baudelaire, un culto que en los años treinta aún podía él localizar con suficiente claridad en la propaganda nazi (2008d: 95). Entre toda la bibliografía del siglo XIX que Benjamin consultó para su Libro de los pasajes es difícil que no se encontrase con esa nueva forma de esprit que denunciaron los hermanos Goncourt: «risa terrible, rabiosa, febril, malvada ...» (1868: 42). Con ese espíritu quemante más que chisposo, la confianza de Benjamin se pone en entredicho incluso cuando Baudelaire asegura que "el Sabio tiembla por haber reído", que "teme a la risa como teme a los espectáculos mundanos» (1868: 132). Así que la risa no escapa del miedo, y por ello incluso la del propio Baudelaire vendría también a contradecir de golpe la idea de que existe una risa dichosa que nada sabe de culpas, como Benjamin pretendía. Esta risa pánica proviene siempre de una superioridad, y lo hace además por partida doble, ya que según había explicado Baudelaire -y Benjamin leyó con mucha atención-, la risa puede ser expresión de superioridad de un hombre sobre otro hombre puntualmente castigado a carcajada suelta, como se suelta un sarcasmo o como se suelta una bofetada; pero no sólo eso, pues también puede mostrar algo incluso más grotesco: la risa puede mostrar, como decía Baudelaire, «la superioridad del hombre sobre la naturaleza". Y esto hasta el punto de encontrar su más perfecta fórmula artística en la completa gratuidad del l'art pour l'art, porque cuando se ríe uno de esa manera hasta perder el sentido, eso es, según Baudelaire, «lo cómico absoluto» (1868: 375).

Queda claro entonces que Benjamin había pensado bien esa risa que castiga. Queda claro, digo, sobre todo por el modo en que también él entendió la doctrina de l'art pour l'art, para la cual, según apuntaba, no hay otro destino más perfecto que el de la guerra, pues «tal es al fin sin duda la perfección total de l'art pour l'art” (2008c: 85). Y por cierto que con este apunte también se posicionaba Benjamin frente a otra de las tendencias vanguardistas de su época, pues es de sobra conocido el modo en que él situaba el epítome de l'art pour l'art en el mismo lugar que ocupaba, por ejemplo, un Filippo Tommaso Marinetti al empeñarse en seguir estetizando la guerra aún en 1935 (2008c: 84). De hecho, en ese "cómico absoluto", la guerra bien podía comenzar con una carcajada idiota y fosforescente, como precisamente dijo Gabriele d'Annunzio que lo era Marinetti; porque el replegarse de l'art pour l'art no sólo le hace al arte un lugar autónomo y separado de la vida diaria, sino que se convierte en un excelente dispositivo de apropiación, de tal manera que puede arrastrarlo todo a la esfera de lo estético. Tal vez no haya mejor testimonio de ello que el de una vanguardia lanzada a la guerra para glorificarla, no sólo como lo hizo Marinetti, sino como lo hicieron tantos otros poetas y artistas. El hecho de que Umberto Boccioni, cuando a punto estaba de perder su vida en la guerra la observase como espectáculo al punto de afirmar que «sólo existe el arte» resulta lo suficientemente elocuente (1986: 373). Y es que, como Benjamin afirmaba, la Gran Guerra ya había revelado a la humanidad el goce estético de su propia destrucción (2008c: 85). Pero este goce podía no sólo deberse a la belleza de los "cohetes que iluminan la noche», como había dicho Guillaume Apollinaire y no se cansaría de repetir Marinetti; de hecho, para las vanguardias la belleza siempre fue algo del pasado, algo que ultrajar e injuriar, siguiendo el postulado de Rimbaud. Lo que las vanguardias perseguían no era precisamente la belleza, sino algo mucho más potente, y el «fiat ars, pereat mundus» que Benjamin evocaba en el epílogo de su ensayo sobre «La obra de arte en la época de la reproductibilidad técnica" aún puede sonar a broma de mal gusto - ¿no era acaso contra ese buen gusto tan burgués contra lo que las vanguardias se pronunciaron con más intensidad?-.

\section{La risa que ordena}

Hay, sin embargo, otro modo de entender la situación de l'art pour l'art dentro de la rúbrica baudelaireana de lo "cómico absoluto". Y esto se podría observar igualmente desde la afirmación de Benjamin según la cual el fascismo encontró en la guerra una meta perfecta que ofrecer a las masas «sin tocar las relaciones de propiedad» (2008c: 83), pues algo así también hace pensar que l'art pour l'art redundaba en ese perfecto complementario que Hermann Broch le encontró también en esos años: el business is business (1974: 82). 
Creo que Benjamin habría estado muy de acuerdo con ese paralelismo y, de hecho, el colofón de la conferencia sobre «El autor como productor» es en este punto de lo más elocuente, pues en él acababa por saldar cuentas tanto con el fascismo como con el capitalismo precisamente advirtiendo que la lucha revolucionaria no se juega en la falsa contraposición entre el capitalismo y el espíritu, o dicho de otro modo, entre el aparente materialismo del business is business y el evidente espiritualismo de l'art pour l'art. Claro que este punto hay que hilar muy fino, pues al denunciar esa falsa contraposición, Benjamin tocaba igualmente de soslayo la propia concepción de lo «cómico absoluto» en l'art pour l'art, tal como había explicado Baudelaire que procede de «la superioridad del hombre sobre la naturaleza». Y es que la aparente contraposición entre el fascismo y el capitalismo se deconstruye precisamente desde el tipo de relación que en ambos órdenes se establece entre el hombre y la naturaleza y, por ende, en ese punto límite que surge con las sacudidas del diafragma, al borde mismo de la palabra, es decir con la risa. Porque contenerla en este punto resulta más difícil que hacerla saltar, lo que aquí está en juego son los propios modos de hacer reír, es decir, la propia técnica en el límite de ese concepto que Benjamin advertía tanto en el fascismo como en el capitalismo, a saber: la técnica como «dominio del hombre sobre la naturaleza» (2010b: 88). A fin de cuentas, con qué mayor facilidad se gana a la gente quien sabe hacerla reír... ¿Acaso tendremos aquí que recordar las payasadas que, según Adorno, le valieron a Hitler la simpatía de los alemanes, aumentando incluso su carisma (2004b: 375)? Desde luego, nos apresuramos demasiado si vemos en la risa únicamente un principio de anarquía. Por el contrario, el propio Adorno supo entender, en 1944, que la risa no ha de considerarse como un signo de irrupción de la naturaleza, sino que «en la risa, la ciega naturaleza toma justamente conciencia de sí misma en cuanto tal y se libera con ello de la violencia destructora». Pero tal liberación trae consigo un orden nominal, pues en efecto, «este doble sentido [violento y liberador] de la risa es afín al del nombre, y tal vez los nombres no sean más que risas petrificadas, como aún hoy los apodos, los únicos en los que sobrevive algo del acto originario de la asignación del nombre». Así, para Adorno «la risa está ligada a la culpa de la subjetividad», implica por una parte una "suspensión del derecho», pero «apunta también más allá de este vínculo: promete el camino a la patria» (2006: 126-127).
Lo cierto es que la relación entre la risa y la culpabilidad ya se encontraba consignada en la obra de Henri Bergson, quien acababa por perfilar la risa como una suerte de gesto social educativo, un corrector cuyo solo temor nos impediría distraernos demasiado (2003: 24). El ejemplo de quien anda en las nubes y tras un torpe traspié acaba en el suelo quizás sea el más banal, pero muestra cómo la risa que inmediatamente le sigue al resbalón sería una forma de escarnio sobre el despiste que tan difícil es a veces controlar; tan difícil, quiero decir, que a poco que nos descuidemos puede que un avispado nos saque algún tic y lo imite para mayor alborozo del personal. El asunto se vuelve así problemático desde que observamos -como hacía Bergson- que los gestos que repetimos sin darnos cuenta se deben a una suerte de mecanismo constantemente funcionando tras lo vivo, y que tal mecanismo es, a fin de cuentas, la verdadera causa de la risa (2003: 33-34). Ahora bien, esta consideración educativa de la risa nos obliga a pensarla desde la misma perspectiva en que Benjamin observó el problema de la técnica como relación de dominio del hombre sobre la naturaleza, pues del mismo modo en que él se oponía a tal concepto, igualmente, digo, trataba de mantener la risa en el punto exacto de su liberación. Así preguntaba a propósito de la técnica lo que ahora tenemos que dirigir hacia la risa misma, pues «¿cómo vamos a confiar en un campeón del apaleamiento que dice que el dominio de los niños bajo la opresión de los adultos es el sentido de la educación?» (2010b: 88). Al igual que inmediatamente después de formular esta sencilla pregunta desviaba el concepto de técnica desde «el dominio sobre la naturaleza» hasta el «dominio de la relación de la naturaleza con lo humano», así también podría Benjamin haber abordado su respuesta a la risa entrelazada con la culpa.

\section{De lo que aún puede liberarnos la risa}

Si la risa abre para Benjamin un instante educativo, la violencia que representa -que sin duda es fulminante y destructiva- nada tiene que ver con el escarnio, y menos aún con la culpabilidad. En contraste, la suya es una violencia que cae de inmediato sobre la propia semejanza, pues si nos fijamos bien, nada nos hace reír más que caer en la cuenta de semejanzas tales como las que encontramos, por ejemplo, entre un hombre y un animal -de Grandville a Disney, por ejemplo-, 
pero también en el equívoco que se da por un instante entre sonidos semejantes cuyo significado es totalmente desigual. La naturaleza causa semejanzas pero la facultad (siempre infantil para Benjamin) de percibirlas y aun de producirlas y reproducirlas, la facultad mimética, en definitiva, va más allá de lo estrictamente sensorial. Para Benjamin, las semejanzas que se dan de modo consciente son sólo una mínima parte de los casos en que afloran de modo inconsciente (2007c: 208-215), y, precisamente, que estas últimas se nos vengan de repente al magín, eso es lo verdaderamente descacharrante. En este sentido, Benjamin no deja de estar atento a lo que los románticos como Jean Paul habían escrito sobre el chiste (Witz) y las semejanzas, pero mucho menos parece que se desentendiera del análisis que Freud hizo sobre este asunto, sólo que para Benjamin la risa tendría que ver con lo inconsciente del mismo modo en que también hablaba él de un «inconsciente óptico» a propósito de la técnica cinematográfica (2008c: 77). Desde luego, al señalar esto último no se le puede quitar ojo a su particular forma de entender la técnica, que, ciertamente, produce una physis, como él dice, pero por el simple hecho de que en la physis ya hay operando de algún modo una techné que ni podríamos llamar «humana» ni podríamos llamar «natural», sino que pertenece, en efecto, al dominio de la relación entre ambas esferas. En esa relación, las semejanzas no duran más que un instante, de manera que apenas se reconoce la conexión se produce su desconexión, y así cosquillean nuestra memoria para echar a volar de inmediato.
Por todo esto decía Benjamin que «la risa es un desorden de la articulación» (1977b: 956), porque, debiéndose a la percepción misma de una similitud fugaz y volátil, no solamente brota de las conexiones inesperadas, sino también de su interrupción: la facultad de ver semejanzas puede remitir a un acto mágico, como él dice, pero al mismo tiempo se ofrece como oportunidad para el desencantamiento por medio de una cercanía extrema con el lenguaje. Tal sería la función esencial que Benjamin asignaba a la comedia, que, a fuerza de exponer articulaciones y desarticulaciones, implica al propio comportamiento, pues a la facultad de percibir semejanzas también le corresponde la facultad de hacerse semejante uno mismo. Así, si es al comportamiento mimético a lo que la risa se dirige en el fondo, lo cómico implica también la oportunidad de reconocerse diferente; ofrece, a fin de cuentas, la oportunidad de una desidentificación con la propia posición que uno ocupa en los procesos de producción, y recuérdese que transformarlos era precisamente la tarea fundamental que Benjamin atribuía al autor que pone en duda su propia condición de hombre espiritual. En definitiva, si lo cómico absoluto de l'art pour l'art representa la perfección del dominio del hombre sobre la naturaleza así como el dominio de la logocracia sobre la masa y, en último término, la propia estetización de la política, esa misma risa transformadora coincide con la interrupción que, por un instante, desestabiliza la identificación que subyace en tal movimiento, presentándose entonces como el ahora de una politización del arte.

\section{Bibliografía}

ADORNO, Theodor W. (1998), Minima Moralia, Taurus, Madrid.

- (2004a), Teoría estética, Akal, Madrid.

- (2004b), Escritos sociológicos I, Akal, Madrid.

ADORNO, Theodor W., y BENJAMIN, Walter (1998), Correspondencia (1928-1940), Trotta, Madrid.

ADORNO, Theodor W. y HORKHEIMER, Max (2006), Dialéctica de la llustración, Trotta, Madrid.

AGAMBEN, Giorgio (2005), Profanaciones, Adriana Hidalgo, Buenos Aires.

BALL, Hugo (2005), «Manifiesto inaugural de la primera velada Dadá», La huida del tiempo (un diario), Acantilado, Madrid, 2005, pp. 371372. Traducción ligeramente modificada, «Eröffnungs-Manifest, 1. Dada-Abend. Zürich, 14. Juli 1916», Neue Zürcher zeitung (18. Juli 1916).

BAUDELAIRE, Charles (1868), «De l'essence du rire et généralement du comique dans les arts plastiques», Curiosités esthétiques, Michel Lévy Fréres, París.

BENJAMIN, Walter (1977a), «Der Autor als Produzent», Gesammelte Schriften, Il,1 Suhrkamp Verlag, Frankfurt am Main. 
BENJAMIN, Walter (1977b), «Ms 926», Gesammelte Schriften, Il,1, Suhrkamp Verlag, Frankfurt am Main.

- (1995), Haschisch, Taurus, Madrid.

- (2007a), «Experiencia y pobreza», Obras II/1, Abada, Madrid.

- (2007b), «El surrealismo. La última instantánea de la inteligencia europea», Obras II/1, Abada, Madrid.

- (2007c), «Doctrina de lo semejante», Obras II/1, Abada, Madrid.

- (2008a), «Sobre el concepto de historia», Obras I/2, Abada, Madrid.

- (2008b), «Destino y carácter», Obras II/1, Abada, Madrid.

- (2008c) "La obra de arte en la época de su reproductibilidad técnica», Obras I/2, Abada, Madrid.

- (2008d), «El París del Segundo Imperio en Baudelaire», Obras I/2, Abada, Madrid.

- (2009a), «El autor como productor», Obras II/2, Abada, Madrid.

— (2009b), «¿Qué es el teatro épico? [2]», Obras II/2, Abada, Madrid.

— (2009c), «El narrador», Obras II/2, Abada, Madrid.

- (2009d), «El periódico», Obras II/2, Abada, Madrid.

- (2009e), «Kitsch onírico», Obras II/2, Abada, Madrid.

— (2010a), «Myslowitz, Braunschweig, Marsella», Obras IV/2, Abada, Madrid.

— (2010b), «Calle de dirección única», Obras IV/1, Madrid.

— (2010c), «Infancia en Berlín», Obras IVNol. 1, Abada, Madrid.

BERGSON, Henri (2003), La risa, Losada, Buenos Aires.

BOCCIONI, Umberto (1986), «Carta del 16 de agosto de 1916», en DRUDI GAMBILLO, Maria y FIORI, Teresa (eds.), Archivi del Futurismo, vol. I, De Luca Editore, Roma.

BROCH, Hermann (1974), Poesía e investigación, traducción de Ramón Ibero, Barral, Barcelona.

FREUD, Sigmund (1991), El chiste y su relación con lo inconsciente, en Obras completas, vol. VIII, traducción de José L. Etcheverry, Amorrortu, Buenos Aires.

GONCOURT, Edmond y Jules de (1868), Manette Salomon, A. Lacroix, Verboeckhoben et C ${ }^{\text {ie, }}$ París.

HAUSMANN, Raoul (1999), «Panfleto contra la concepción de la vida en Weimar», en GONZÁLEZ GARCÍA, Ángel; CALVO SERRALLER, Francisco; MARCHÁN FIZ, Simón (eds.), Escritos de arte de vanguardia 1900/1945, Istmo, Madrid. 